\title{
Vancomycin-Resistant MRSA Induced by $\beta$-Lactam Antibiotics in Mansoura University Hospitals, Egypt
}

\author{
Ahmed E.S. Taha* ${ }^{*}$ Mohammad F. Badr, Fikry E.S. El-Morsy and Enas Hammad \\ Medical Microbiology and Immunology Department, Faculty of Medicine, \\ Mansoura University, Egypt \\ *Corresponding author
}

\section{A B S T R A C T}

A major problem in MRSA-infected patients is the co-infection with Gram-negative bacteria which are naturally resistant to Vancomycin (VA) and linezolide (LZD). In the past; the use of a combination of VA and B-lactam antibiotics was one of the solutions for treating of such condition depending on synergism. In the recent years; a class of MRSA that becomes resistant to VA only in the presence of $\beta$-lactam antibiotics (BIVR) has been emerged meaning that there is antagonism. This type of VA resistance is mainly due to

Keywords

Antibiotic

resistance, $B$ -

lactamase, $B-$

lactams, MRSA,

Staphylococcus

aureus,

Vancomycin.

\section{Article Info}

Accepted:

26 October 2017

Available Online:

10 December 2017 stimulation of peptidoglycan metabolism and repair system, by ß-lactams, so rapidly depleting free VA to a level below its MIC. This means that B-lactams should remain intact in BIVR culture, although most MRSA cells are known to produce ß-lactamase, meaning that the BIVRs either did not carry the $\beta$-lactamase gene (blaZ) or this gene was suppressed. The present study aimed for screening for the tendency of VA sensitive MRSA to become VA resistant when exposed to $\beta$-lactams in vitro; as a result, MRSA possessing the capability to become BIVR in vivo can expected. Also, investigating the relation between the "BIVR phenomenon" and the B-lactamase activity. We studied 130 MRSA isolates, identified by the disc diffusion method and MecA gene amplification PCR. The isolates were selected to be VA susceptible with MIC $\leq 2 \mu \mathrm{g} / \mathrm{mL}$. The isolates were subjected to the BIVR screening test, testing the B-lactamase activity and conducting PCR amplification of blaZ gene. BIVR testing of the MRSA strains revealed that $13.8 \%$ of the MRSA strains were BIVR positive while $86.2 \%$ were BIVR negative. All the BIVRs showed an undetectable ß-lactamase activity by nitrocefin test, most of them $(83.3 \%)$ lacked the blaZ gene and the remaining (16.7\%) carried the blaZ gene but showed an undetectable B-lactamase either by nitrocefin test or spectro photometrically, indicating that this gene was down regulated or suppressed in them by certain mechanism. Most $(94.6 \%)$ non-BIVRs carried the blaZ gene and most of them $(79.2 \%)$ actively produced detectable $\beta$-lactamase by nitrocefin test. BIVRs gain vancomycin resistance only in presence of $\beta$-lactam antibiotics, so preserving B-lactams in milieu, by preventing $\beta$ lactamase production, either by lacking or suppressing the blaZ gene.

\section{Introduction}

Immunocompromised patients, such as those suffering from cancer often become infected by Staphylococcus aureus (SA). Particularly the infection by MRSA (Hirao et al., 2012).
Owing to the multi-antibiotic-resistant nature of MRSA, only a few number of antibiotics can be tried; the commonest one is VA or the recently discovered LZD (Boucher et al., 
2010; and Sakai et al., 2010). VA is a glycopeptide that binds to the D-Ala-D-Ala ends of the peptidoglycan structure and its precursors, and so blocks the action of peptidoglycan transpeptidase or penicillinbinding proteins (PBPs), so inhibiting the extension of the peptidoglycan network and bacterial growth (Perkins and Nieto, 1974).

VA is active against Gram-positive bacteria, whereas it is ineffective against Gramnegative bacteria, mainly because of the outer membrane which acts as a penetration barrier (Cunha, 2008).

A major problem in MRSA -infected patients is the coinfection with Gram-negative bacteria, such as Pseudomonas aeruginosa, which is naturally resistant to VA and LZD. The use of a combination of VA and B-lactam antibiotics was one of the solutions for treating of such mixed infections depending on strong synergy (Totsuka et al., 1999).

However in 2000s, the use of this combination therapy has led to the appearance of MRSA that is resistant to VA only in the presence of B-lactam antibiotics, which is called ' $B$-lactam antibiotic-induced VA resistant MRSA' (BIVR) (Hanaki et al., 2005).

BIVR can occurs because the use of B-lactam antibiotics promotes peptidoglycan metabolism and repair systems producing much peptidoglycan precursors such as lipidintermediate II with free D-Ala-D -Ala terminals that represent target over production for the antibiotic VA. Consequently, the concentration of free VA in milieu is lowered below its MIC (target over production) and the bacteria begin to grow under such conditions (Yanagisawa et al., 2009).

It is generally assumed that most MRSA cells resist the $B$-lactam antibiotics mainly by production of either PBP2' (PBP2a) (Pinho et $a l ., 2001$ ), or B-lactamase, therefore B-lactam antibiotics in the blaZ gene positive MRSA cultures are rapidly hydrolysed (Lowy, 2003).

However, the "BIVR phenomenon" is induced only in the presence of B-lactam antibiotics, suggesting that B-lactam antibiotics in the BIVR cultures remain intact. The offered explanations are:

The non- BIVRs carried a plasmid having the B-lactamase gene (blaZ), but the BIVRs did not; or

Both BIVRs and non- BIVRs carried a blaZbearing plasmid, but the production of active B-lactamase in BIVRs was down regulated with production of a low level of $B$-lactamase (Hirao et al., 2012).

\section{Objectives}

Screening for the tendency of VA sensitive MRSA to become VA resistant when exposed to $\beta$-lactams in vitro; as a result, MRSA possessing the capability to become BIVR in vivo can expected. Also, investigating the relation between the "BIVR phenomenon" and the $B$-lactamase activity.

\section{Materials and Methods}

\section{Bacterial strains used and culture conditions}

This study was enrolled over a period of 12 months. During the $1^{\text {st }} 6$ months, 130 MRSA were isolated from patients with clinically suspected nosocomial infections, from different departments of the Mansoura University Hospitals (MUHs) dealing with the Medical diagnostics and infection control unit (MDICU) in the microbiology and Immunology department, Faculty of Medicine, Mansoura University, Egypt. The 
isolates were identified and obtained as pure growth from the clinical samples by the classical bacteriological methods and biochemical reactions (Cheesbrough, 2006; Forbes et al., 2007), and by the disc diffusion method as recommended by the CLSI (2014), then confirmed by $M e c A$ gene amplification PCR. The isolates were selected to be VA susceptible with MIC $\leq 2 \mu \mathrm{g} / \mathrm{mL}$. The isolates were subjected to the BIVR screening test, testing the $\beta$-lactamase activity either by a nitrocefin paper disk or by a spectrophotometric method and conducting PCR amplification of blaZ gene. Culture media (Oxoid) used were Mueller-Hinton (MH) broth, Mu3 agar (brain-heart infusion agar plate supplemented with $4 \mu \mathrm{g} / \mathrm{ml} \mathrm{VA}$ ) and $\mathrm{MH}$ agar, depending on the purpose, and bacteria were incubated at $35^{\circ} \mathrm{C}$ for the desired period of time.

\section{Identification of methicillin resistance by Cefoxitin-based method (CLSI, 2014)}

MH agar plates (diameter, $90 \mathrm{~mm}$ ) were allowed to dry in the incubator (at $35^{\circ} \mathrm{C}$ ) for 10-30 minutes.

The inoculum was prepared using direct colony suspension method and adjusted to match 0.5 McFarland turbidity standard.

Optimally, within 15 minutes after adjusting the turbidity of the inoculum suspension, a sterile cotton swab was dipped into the suspension, rotated several times and pressed firmly on the inside wall of the tube above the fluid level and evenly streaking all the surface of the plate.

The plates were allowed to dry in the incubator at $35^{\circ} \mathrm{C}$ for 15 minutes before the disks laid on the surface.

According to the CLSI recommendations, using a 30- $\mu \mathrm{g}$ cefoxitin disk, resistance was determined when the diameter of the growth inhibition zone is $\leq 21 \mathrm{~mm}$.

The plates were then inverted and incubated for $24 \mathrm{hs}$ at $35^{\circ} \mathrm{C}$.

The diameter of the growth inhibition zone around the cefoxitin disk was detected using reflected light.

\section{MecA gene amplification PCR}

Chromosomal DNA extraction was done according to (Aushbel et al., 1990) to get the DNA templates. $M e c A$ gene amplification by PCR was done using a pair of primers (Sigma) selected according to (Bignardi et al., 1996) and the sequence of the primer used was:

\section{$F:$ 5'-CTCAGGTACTGCTATCCACC-3' $R:$ 5'-CACTTGGTATATCTTCACC-3'}

The PCR reaction was carried out in a final volume of $25 \mu$ l containing:

Twelve and half $\mu$ l of Taq PCR Master Mix after being briefly vortexed to avoid localized differences in salt concentration.

The primer solutions were thawed on ice and mixed well before use. One $\mu l$ of each primer was added to the PCR tube.

Five $\mu l$ of template extracted DNA was added to each tube.

Five and half $\mu$ l of nuclease-free water were added (Table 1).

Agarose gel (1.5\%) electrophoresis of the amplified MecA gene was done according to (Davis et al., 1986) using the DNA molecular marker (100 bp DNA Ladder; Lonza Rockland.Inc, USA) to detect the expected (448 bp) bands visualised by staining with ethidium bromide (EB). 


\section{Determination of the MIC of VA on MRSA}

This was done according to (Sarker et al., 2007) using a microtitre plate incorporating resazurin as an indicator of bacterial growth

\section{The BIVR screening test}

MRSA bacteria were grown in MH broth supplemented with $1 \mu \mathrm{g} / \mathrm{ml}$ ceftazidime overnight at $35^{\circ} \mathrm{C}$.

Bacterial suspension were adjusted to $(\mathrm{A} 578 / 1 \mathrm{~cm}=0.3)$ then $0.1 \mathrm{ml}$ of the bacterial suspension was streaked on a brain-heart infusion agar plate supplemented with 4 $\mu \mathrm{g} / \mathrm{ml}$ VA (Mu3 agar, BIVR detection medium).

A paper disk (8- $\mathrm{mm}$ in diameter) supplemented with $80 \mu \mathrm{l}$ of $0.1,1.0$, or 10.0 $\mu \mathrm{g} / \mathrm{ml}$ ceftazidime was placed on the agar plate.

Bacteria showing a growth zone around the disks were considered to be BIVR.

For more confirmation; 'the Phasing out experiment' was done.

\section{The Phasing-out of the BIVR phenomenon}

The BIVRs were transferred to antibiotic-free $\mathrm{MH}$ agar and the plate was incubated at $37^{\circ} \mathrm{C}$ for 24 hours.

Bacterial suspensions from the plates were inoculated again on antibiotic-free $\mathrm{MH}$ agar and incubated for 24 hours at $37^{\circ} \mathrm{C}$.

This serial transfer and culture was continued for 5 successive days.

Every day, the culture was exposed to 'BIVR screening test' to test the fate of the organism (Hirao et al., 2012).
Qualitative determination of B-lactamase activity by nitrocefin tests in both BIVRS and Non BIVRS (Murray, 1998)

A paper disk (8-mm in diameter) supplemented with $80 \mu \mathrm{l}$ nitrocefin (550 $\mu \mathrm{g} / \mathrm{ml})$ was placed on a glass slide using forceps, then 5 bacterial colonies were picked using a sterile bacteriological loop and were spreaded on the disc.

Changing the colour of the disk from yellow to pink within 5 minutes indicates positive production of ß-lactamase by the tested strains, these bacteria were judged to be nitrocefin positive.

\section{Detection of the blaZ gene by PCR in both} BIVRS and Non BIVRS

\section{Plasmid DNA extraction}

Bacterial were grown overnight in $5.0 \mathrm{ml}$ brain- heart infusion broth supplemented with $10 \mu \mathrm{g} / \mathrm{ml}$ ceftazidime, then centrifugated at $6000 \times \mathrm{g}$ for $10 \mathrm{~min}$.

Bacteria were treated with $50 \mu \mathrm{g} / \mathrm{ml}$ lysostaphin at $37^{\circ} \mathrm{C}$ for $40 \mathrm{~min}$.

Plasmid DNA was extracted using the (Thermo Scientific Gene JETT M Plasmid Miniprep Kit), according to the manufacturer's instructions. Then, the DNA was analysed by agarose gel (1.5\%) electrophoresis, stained with EB and visualised under UV light.

blaZ gene amplification by PCR (Table 2)

This was done using a pair of primers (Sigma): Selected according to (Hirao et al., 2012) and the sequence of the primer used was:

F 5'-ACTTCAACACCTGCTGCTTTC-3' 
$R$ 5'-TGACCACTTTTATCAGCAACC-3' Agarose gel (1.5\%) electrophoresis of the amplified blaZ gene was done according to (Davis et al., 1986) using the DNA molecular marker (100 bp DNA Ladder; Lonza Rockland.Inc, USA) to detect the expected (173 bp) bands visualised by staining with EB.

\section{Quantitative}

spectrophotometric

measurement of $B$-lactamase level in BIVRS and non BIVRS that are blaZ gene +ve and nitrocefin -ve

It was carried out according to Hirao et al., (2012) as follows:

Bacterial were grown overnight at $37^{\circ} \mathrm{C}$ in a 4-ml Nutrient broth supplemented with10 $\mu \mathrm{g} / \mathrm{ml}$ ceftazidime.

Bacterial were centrifugated at $10000 \times \mathrm{g}$ for $10 \mathrm{~min}$.

Pellets were washed once with $4 \mathrm{ml}$ sodium phosphate buffer $(50 \mathrm{mM}, \mathrm{pH} 7.2$, containing $145 \mathrm{mM}$ sodium chloride), then were suspended in $400 \mu$ l of the same buffer.

More than $99 \%$ of the B-lactamase was associated with the centrifuged bacterial pellets and so the assay was carried out using the suspension of the washed bacterial pellets.

A pair of $1.0-\mathrm{ml}$ reaction mixtures was prepared containing $10 \mu \mathrm{l}$ bacterial pellet suspension, $10 \mu 100 \mathrm{mM}$ EDTA and $880 \mu \mathrm{l}$ $50 \mathrm{mM}$ sodium phosphate buffer ( $\mathrm{pH} 7.0$ ). The reaction was initiated by adding $100 \mu \mathrm{l}$ $500 \mu \mathrm{M}$ nitrocefin and 1 tube was incubated for 3 minutes and the other for 13 minutes.

The tubes were centrifuged at $12000 \times \mathrm{g}$ for 2 minutes and the clear supernatant was separated. The colour development was determined at 5 and 15 minutes by measuring the absorbance at wave length 486 (A486). The reaction velocity per minute was calculated by subtracting A486 at 5 minutes from that at 15 minutes divided by 10 .

The colour development from 5 to 15 minutes should be linear under these conditions.

For the bacteria with no ß-lactamase activity, $100 \mu$ bacterial pellet suspension was used and incubated at $24^{\circ} \mathrm{C}$ for 30 minutes.

\section{Statistical analysis}

The $\chi^{2}$ was carried out using a computer programme embedded in Microsoft Excel. Tests were considered significant if $p$ value < 0.05 at confidence interval $95 \%$.

\section{Results and Discussion}

130 MRSA strains were isolated from patients with clinically suspected nosocomial infections, from different departments of the MUHs dealing with the MDICU. The 130 MRSA isolates, identified by the disc diffusion method and $M e c A$ gene amplification PCR. The isolates were subjected to the BIVR screening test, testing the $\beta$-lactamase activity either by a nitrocefin paper disk or by a spectrophotometric method and conducting PCR amplification of blaZ gene.

In photo (4), pink colour indicated bacterial growth and blue means inhibition of growth.

C1: sterility control (column with all solutions with the exception of the bacterial solution adding $10 \mu \mathrm{L}$ of nutrient broth instead); no bacteria.

C2: control without drug (column with all solutions with the exception of the test antibiotic; VA); bacterial growth. 
C3: positive control (column with a broadspectrum antibiotic, usually ciprofloxacin, in serial dilution as positive control)

T1-T5: Tests (VA in serial dilution in wells $1-12+$ resazurin + bacteria).

The tendency of 130 MRSA strains to become BIVRs was surveyed in MUHs, Egypt. BIVR testing of the MRSA strains revealed that $13.8 \%$ of the MRSA strains were BIVR positive [18 BIVRs /130 MRSA strains] and $86.2 \%$ of the MRSA strains were BIVR negative $[112$ non-BIVRs /130 MRSA strains].

The frequency of BIVRs detection among MRSA strains in MUHs in this study seemed to be higher than the average rate reported by Yamaguchi et al., (2003) (5.5\% [54 BIVRs/986 MRSA strains] in 14 general hospitals in Japan) and by Hirao et al., (2012) [7.0\% (25 BIVRs/353 MRSA strains)]. This is likely due to the fact that many of the inpatients in MUHs may be subjected to antibiotic treatment for prolonged periods of time. Thus, it is most probably that BIVRs were selected by the use of VA and $\beta$-lactam antibiotics.

Tests on 18 BIVRs revealed that; all the 18 BIVRs showed an undetectable B-lactamase activity by nitrocefin test (100.0\% [18/18]), 15 of them lacked the blaZ gene $(83.3 \%$ $[15 / 18]$ ), and the remaining 3 carried the blaZ gene $(16.7 \%$ [3/18]) but showed an undetectable $\beta$-lactamase by nitrocefin test or spectrophotometrically, indicating that this gene was down regulated or suppressed in these 3 strains by certain mechanism. Tests on 112 non-BIVRs revealed that; Most nonBIVRs carried the blaZ gene (94.6\% [106 /112]) and most of them actively produced detectable $\beta$-lactamase activity by nitrocefin test (79.2\% [84/106]) (Table 3; Fig. 1 and 2).

Photo.1 Antibiotic susceptibility test of MRSA isolates by DD method

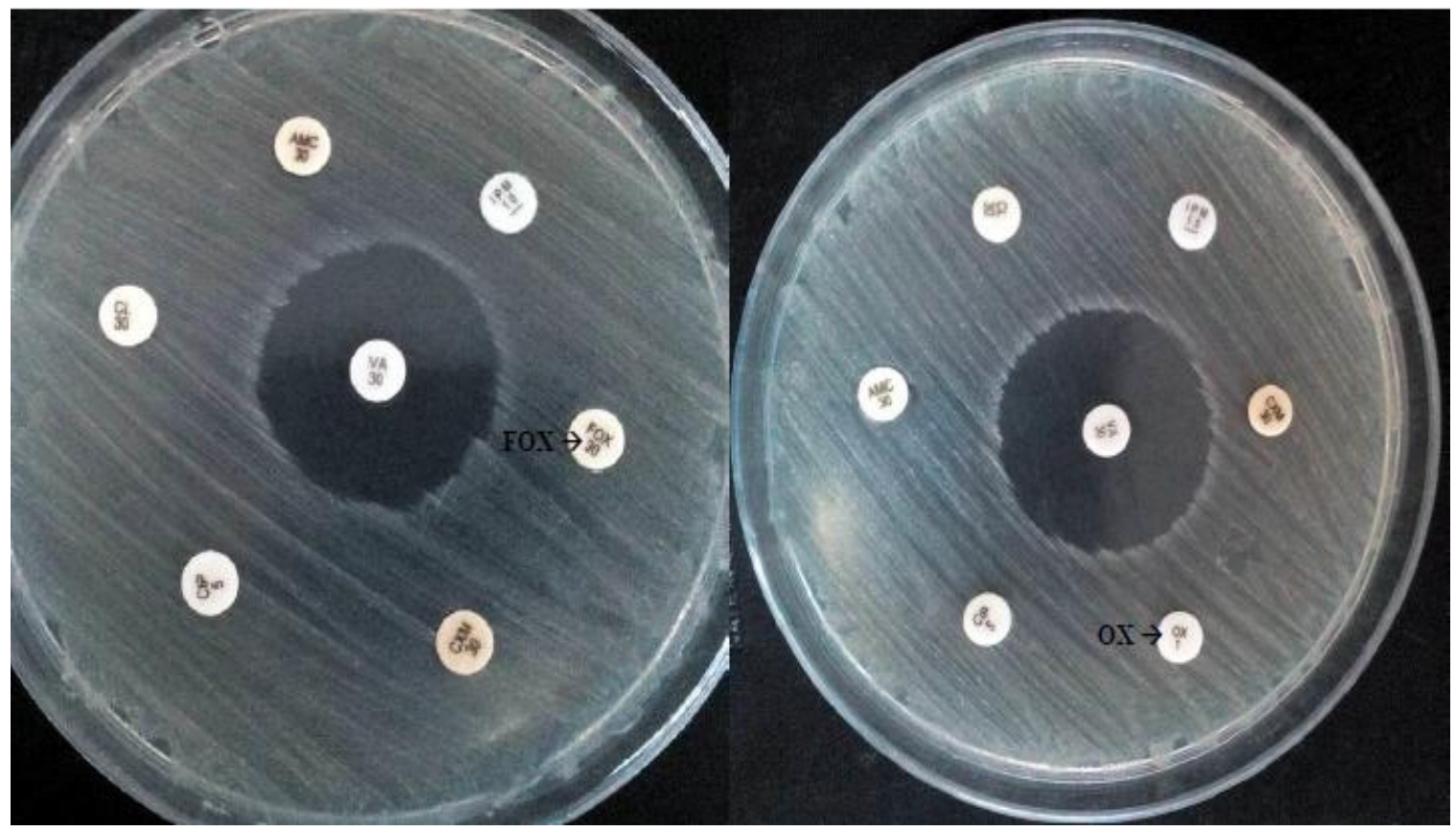


Photo.2 Agarose gel electrophoresis of amplified mecA DNA by PCR

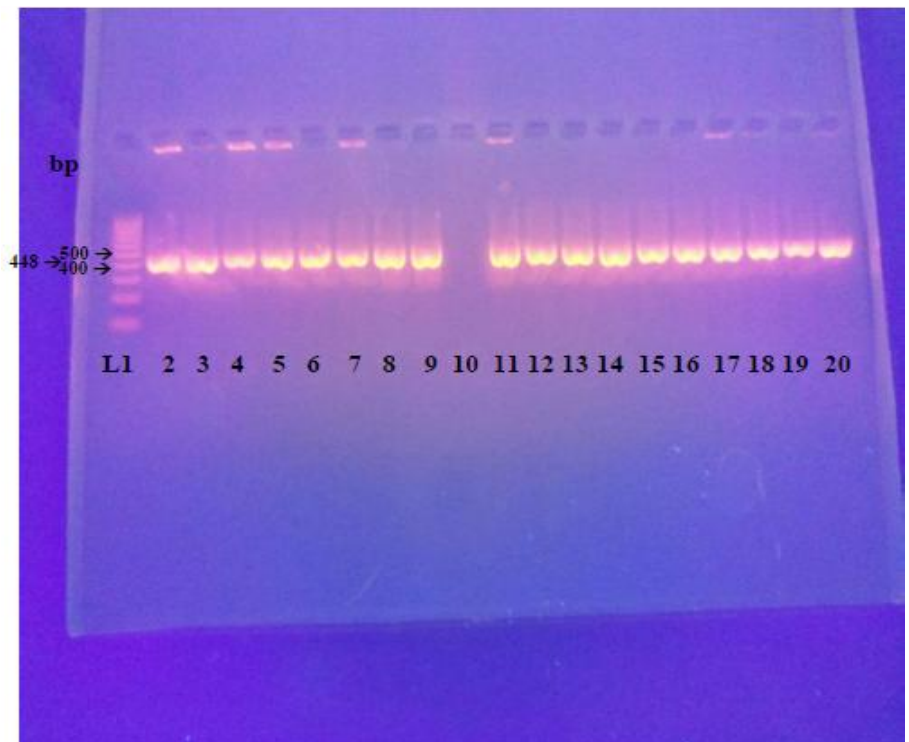

The PCR product separated by size and visualized by staining with EB. Lane 1, DNA molecular marker (100 bp DNA Ladder; Lonza Rockland.Inc, USA). Lanes 2, 3, 4, 5, 6,7, 8,9, L11, 12, 13, 14,15,16,17, 18, 19 and 20 show specific DNA bands of MRSA mecA gene (448 bp), while Lane 10 show no specific DNA bands of MRSA mecA gene.

Photo.3 The BIVR screening test: The organisms were streaked on agar plates impregnated with $4 \mu \mathrm{g} / \mathrm{ml} \mathrm{VA}$

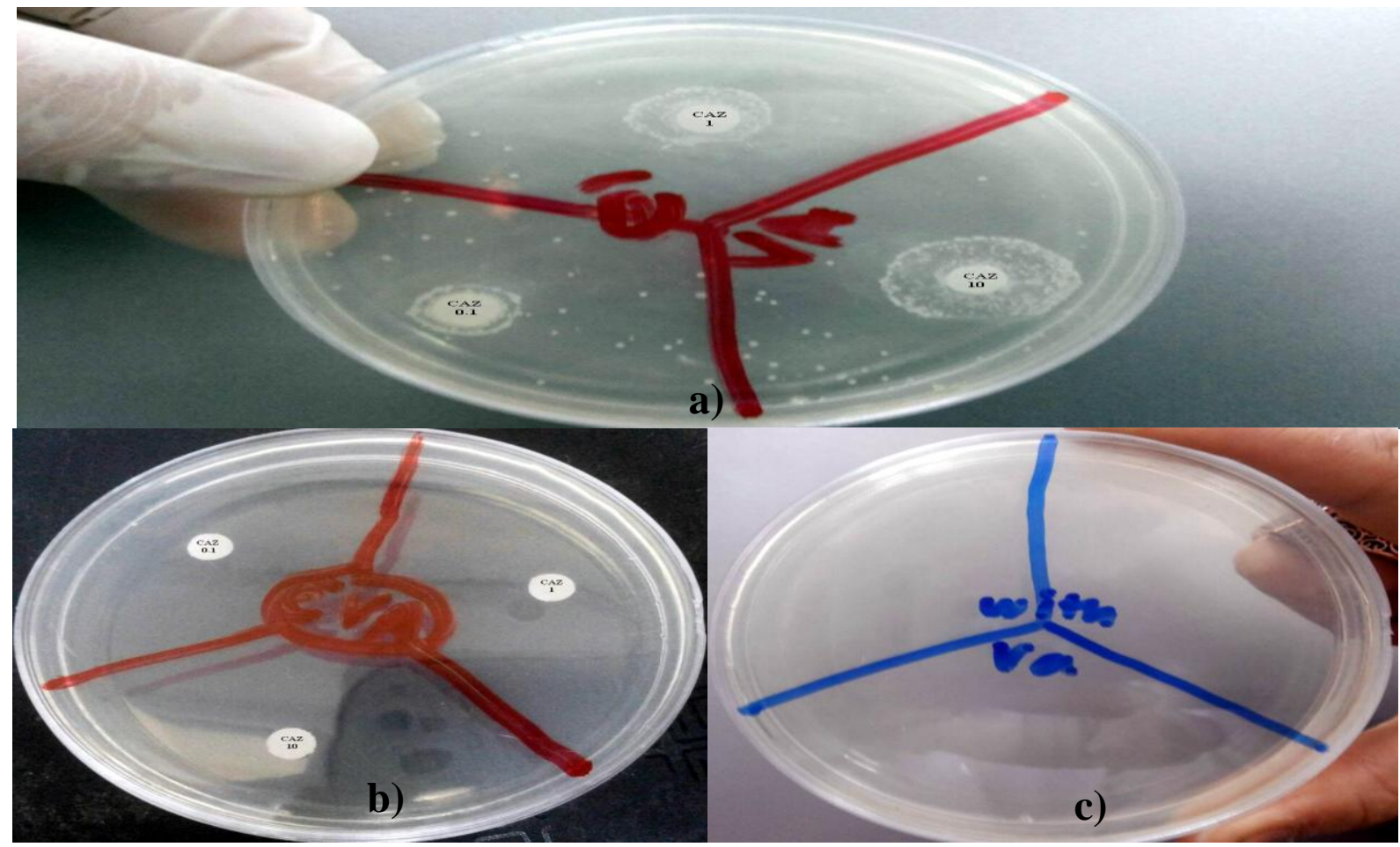

A: When ß-lactam impregnated disks with concentrations of $0.1,1.0$ and $10 \mu \mathrm{g} / \mathrm{ml}$ ceftazidime were placed on the agar, the isolates grew around the disks, Thus the BIVR property was confirmed.

$\mathrm{B}$ and C: The Non BIVRs were VA-susceptible and did not grow on the VA-containing plates in the presence or absence of B-lactam-antibiotic impregnated disks 
Photo.4 VA MIC of MRSA before and after the BIVR screening test in microtitre plate incorporating resazurin as an indicator of bacterial growth
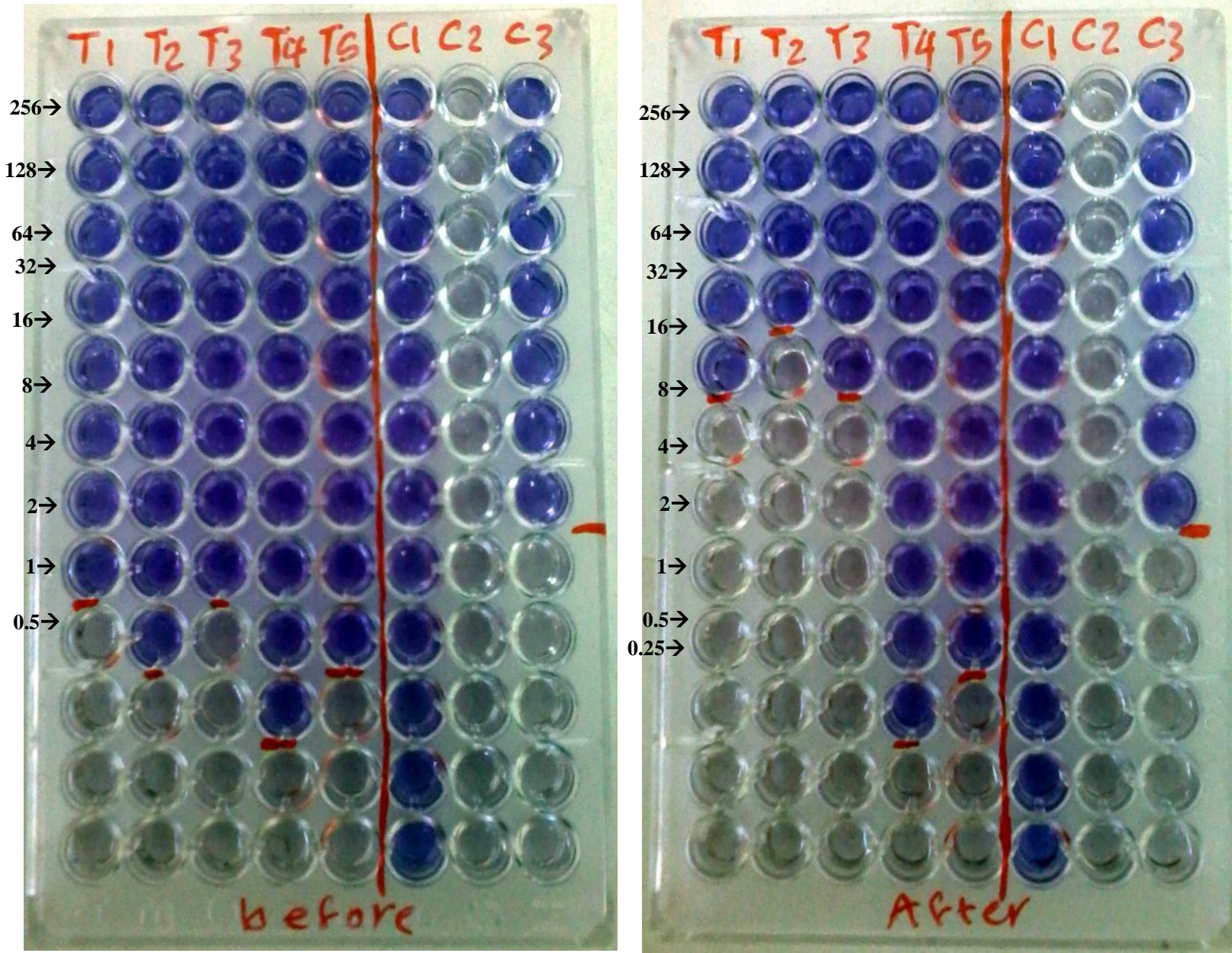

a) Before BIVR screening test: The organisms were sensitive to VA (VA MICs were $\leq 2 \mu \mathrm{g} / \mathrm{mL}$ ).

b) After BIVR screening test: BIVRs (T1,T2,T3); (VA MICs became $\geq 16 \mu \mathrm{g} / \mathrm{mL}$ ) while Non BIVRs (T4,T5); (VA MICs remained $\leq 2 \mu \mathrm{g} / \mathrm{mL}$ )

Photo.5 The Phasing-out of the BIVR phenomenon

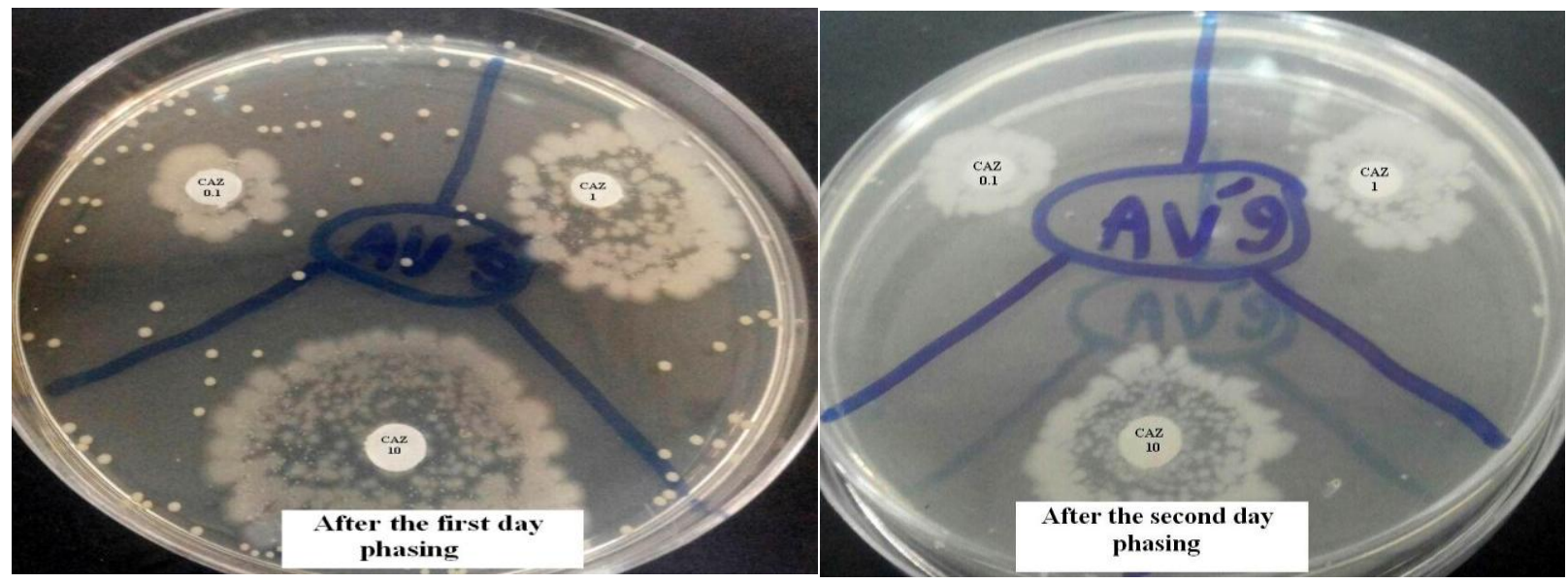




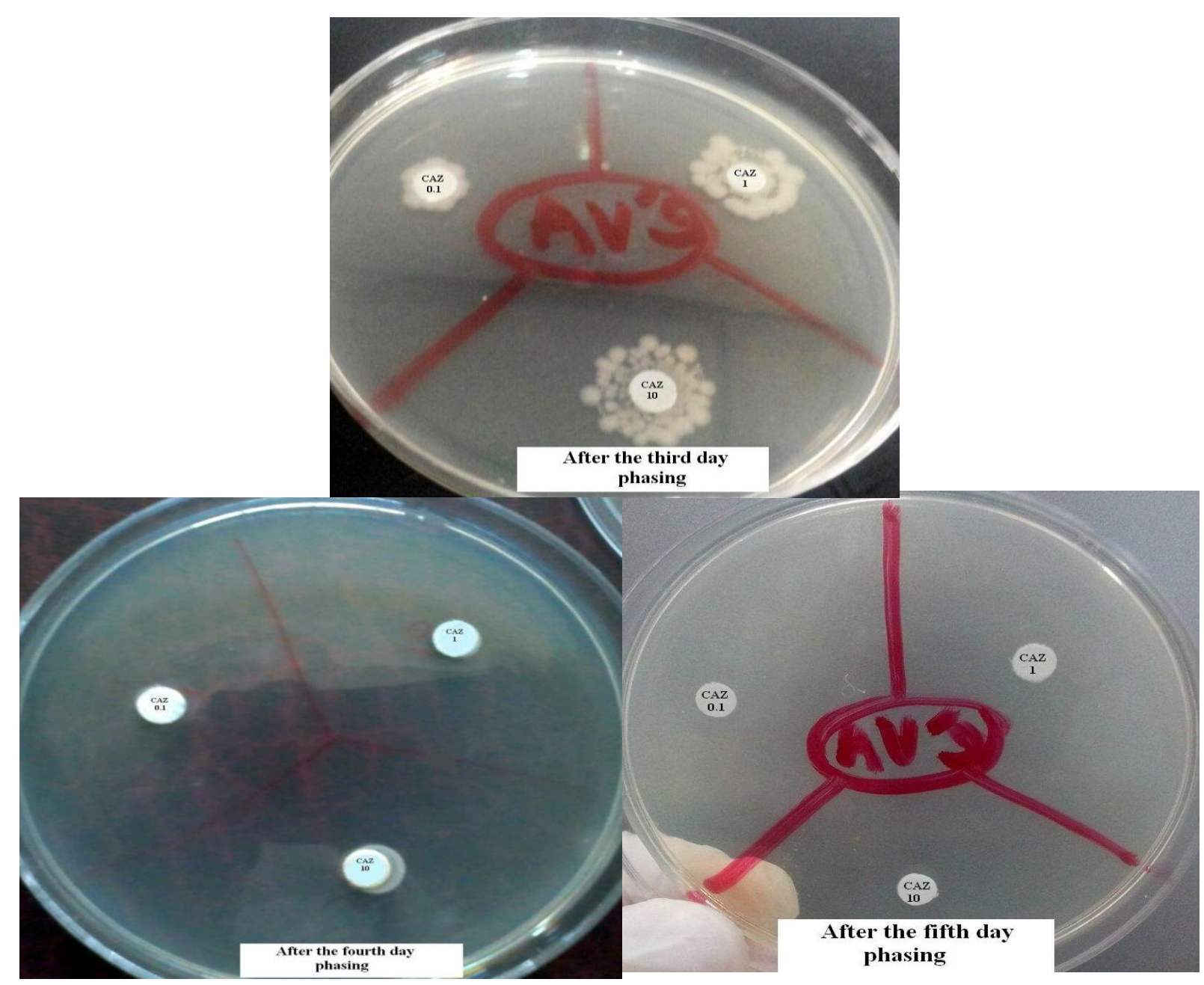

The BIVR cell properties were phased out by 5 successive days of passages on antibiotic-free MH agar. These bacteria, whose BIVR properties were gradually phased out, showed the non-BIVR phenotype (with MIC = 2 $\mu \mathrm{g} / \mathrm{mL}$ ) when subjected to the BIVR test again

Photo.6 Nitrocefin test

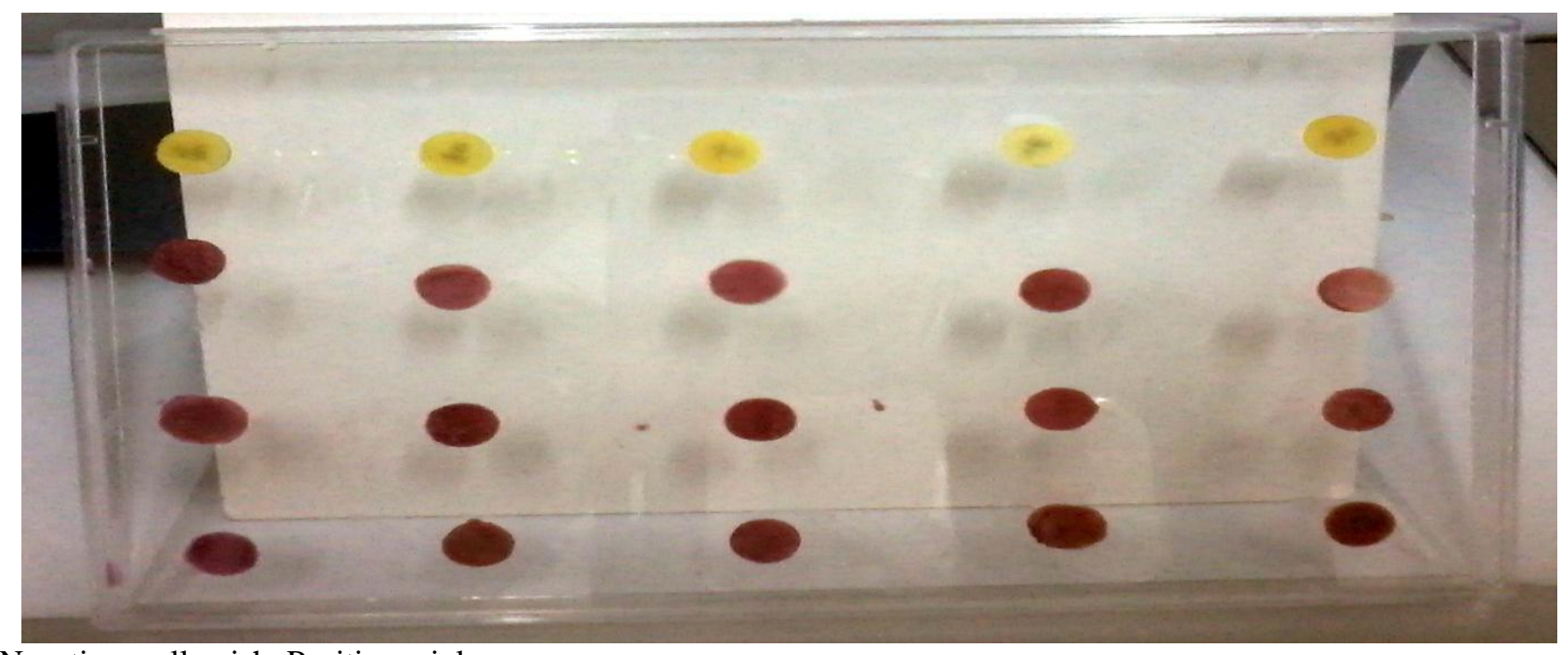

Negative; yellowish. Positive; pink. 
Photo.7 Agarose gel electrophoresis of amplified blaZ gene DNA by PCR

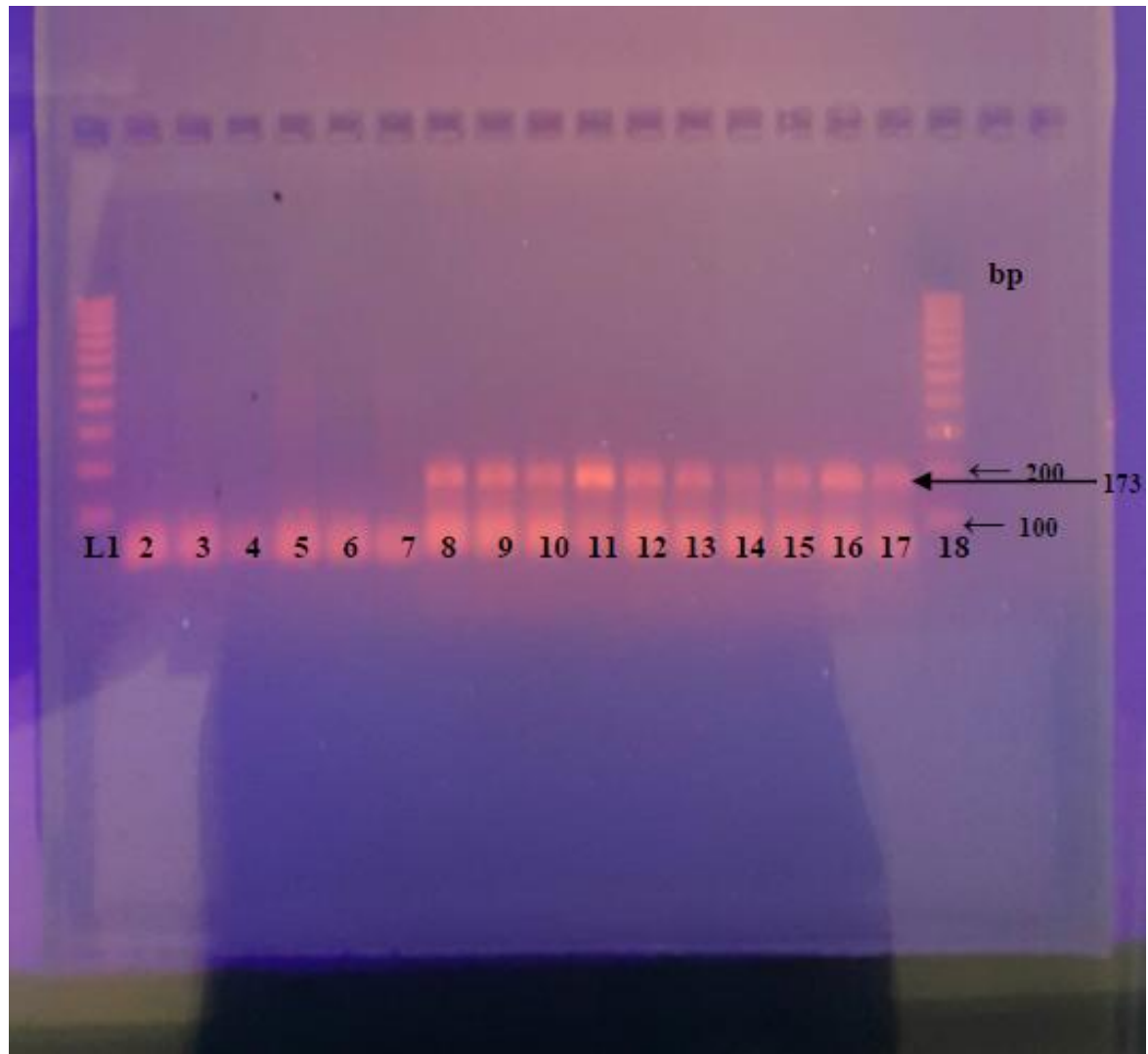

The PCR products were separated by size and visualized by staining with EB. Lane 1and 18 show the DNA molecular marker (100 bp DNA Ladder; Lonza Rockland. Inc, USA). Lanes 8, 9, 10, 11, 12, 13, 14, 15,16 and 17 show specific DNA bands of MRSA blaZ gene (173bp), while Lanes 2, 3, 4, 5 and 7, show no specific DNA bands of MRSA blaZ gene.

Fig.1 Frequency of BIVRs and non-BIVRs among MRSA which are sensitive to VA

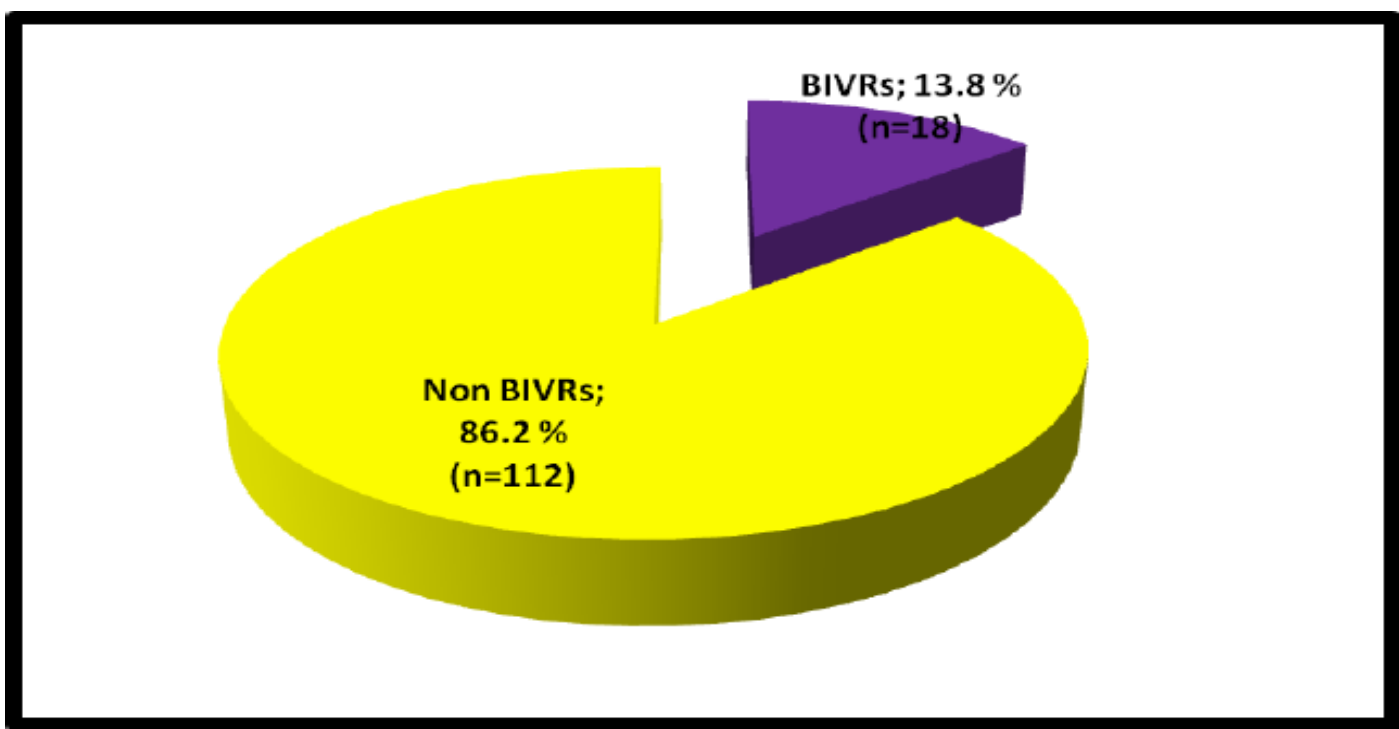

MRSA isolates that have tendency to become BIVRs (BIVRs) represented (13.8\%) while MRSA isolates that didn't have tendency to become BIVRs (Non BIVRs) represented (86.2\%). 
Fig.2 Distribution of BIVR and non-BIVR isolates according to the type of nosocomial infection

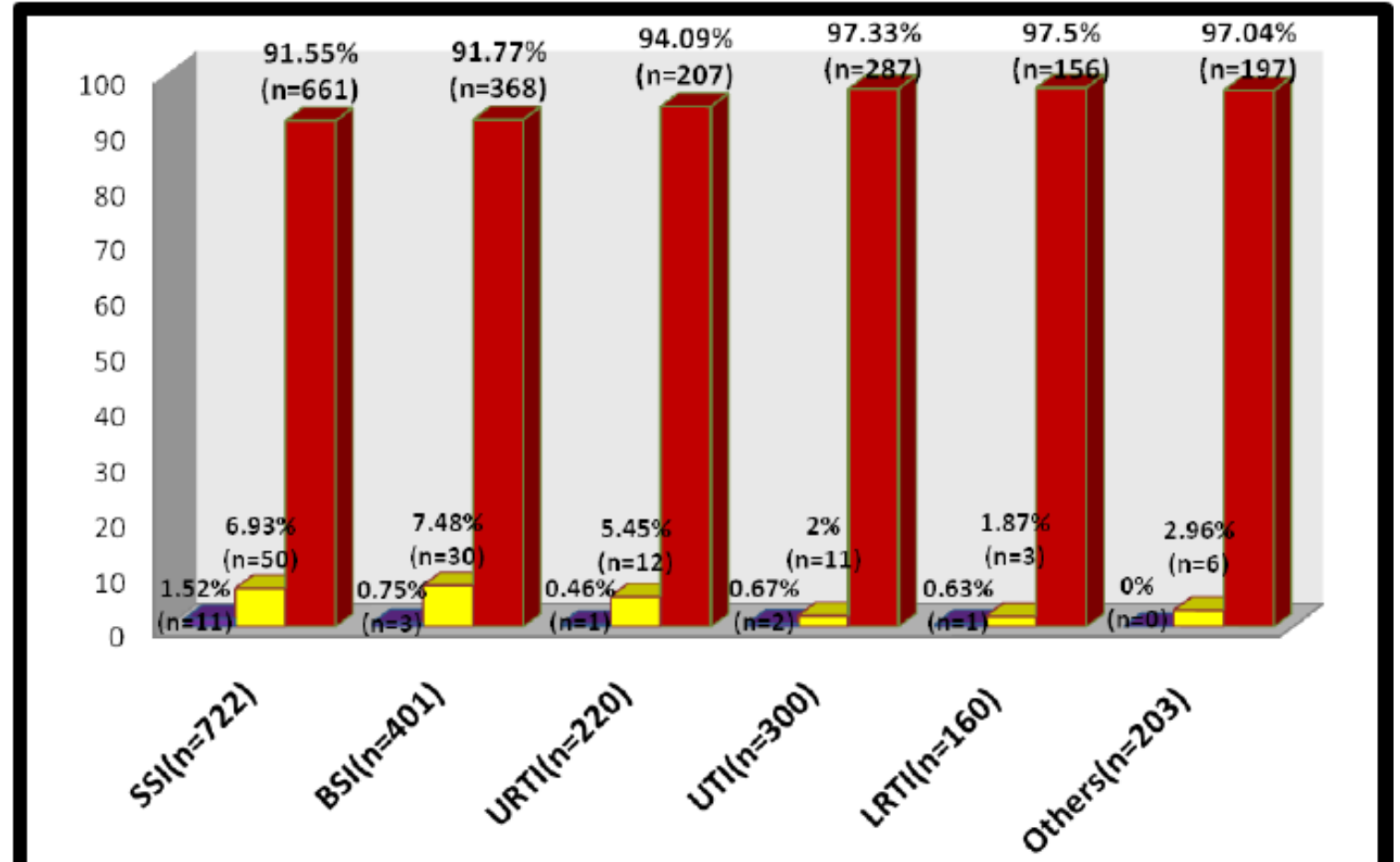

BIVRS 0.9\%(n=18) $\square$ Non BIVRS 5.58\%(n=112) @ Other pathogens $93.52 \%(n=1,876)$

SSI was the most prevalent site for the BIVRS and represented (1.52\%). BSI was the most prevalent site for the non-BIVRS and represented $(7.48 \%)$.

Fig.3 Comparison between the blaZ gene and $\beta$-lactamase activity detected by Nitrocefin test in BIVR and non-BIVR isolates

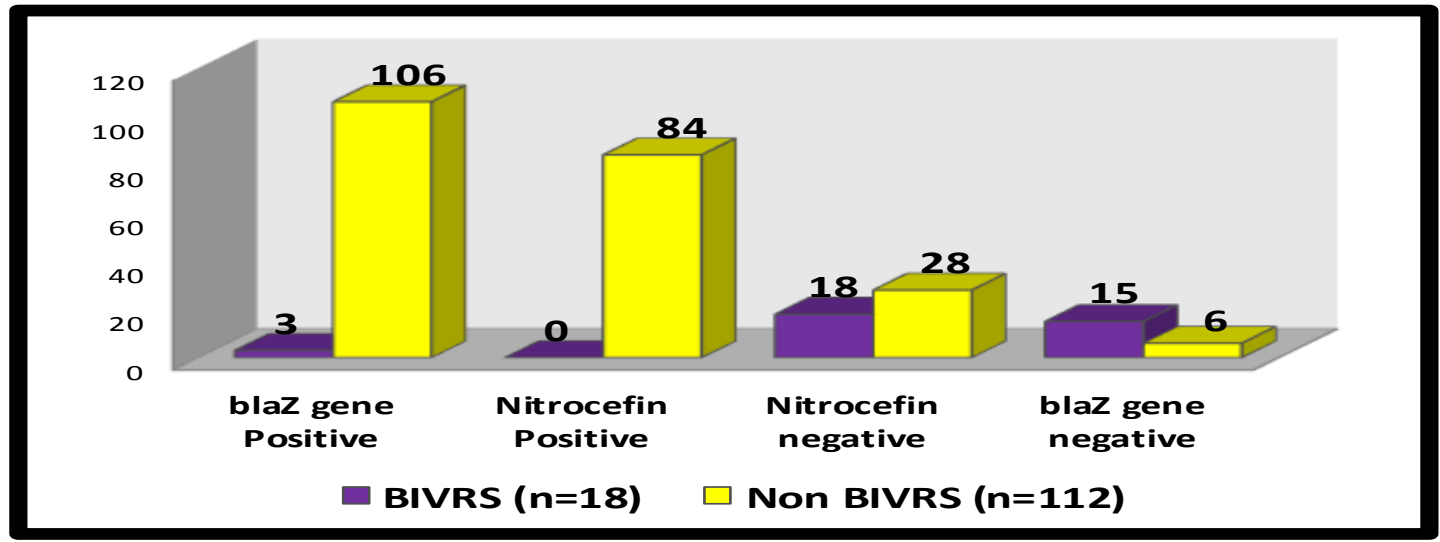

A statistically significant difference in the occurrence of the blaZ gene and B-lactamase activity between the BIVRs and non-BIVRs was found with $P$ value $<0.05$ by the $\chi^{2}$ test. These results clearly showed a tendency for BIVRs to lack the blaZ gene and not produce active B-lactamase, whereas most non-BIVRs possessed the blaZ gene and a significant fraction $(75.0 \%)$ produced B-lactamase. 
Table.1 MecA gene amplification PCR; The thermal cycler program was adjustedand proceeded as follows

\begin{tabular}{|l|c|c|c|c|c|}
\hline The & Initial & \multicolumn{2}{|c|}{ Three step cycling x 30 times: } & Final \\
\cline { 3 - 5 } step: & denaturation & Denaturation & Annealing & Extension & extension \\
\hline Duration & 5 minutes & 30 seconds & 30 seconds & 30 seconds & 10 minutes \\
\hline Temperature & $95^{\circ} \mathrm{C}$ & $94^{\circ} \mathrm{C}$ & $42^{\circ} \mathrm{C}$ & $72^{\circ} \mathrm{C}$ & $72^{\circ} \mathrm{C}$ \\
\hline
\end{tabular}

Table.2 blaZ gene amplification by PCR; The PCR reaction was carried out in a final volume of $25 \mu \mathrm{l}$ and the thermal cycler program was adjustedand proceeded as follows

\begin{tabular}{|l|c|c|c|c|c|}
\hline The & Initial & \multicolumn{2}{|c|}{ Three step cycling x 30 times: } & Final \\
\cline { 3 - 5 } step: & denaturation & Denaturation & Annealing & Extension & extension \\
\hline Duration & 30 seconds & 5 seconds & 10 seconds & 10 seconds & 7 minutes \\
\hline Temperature & $98^{\circ} \mathrm{C}$ & $98^{\circ} \mathrm{C}$ & $57^{\circ} \mathrm{C}$ & $72^{\circ} \mathrm{C}$ & $72^{\circ} \mathrm{C}$ \\
\hline
\end{tabular}

Table.3 Quantitative $\beta$-lactamase level in selected isolates which are blaZ gene Positive and nitrocefin test negative

\begin{tabular}{|c|c|c|c|}
\hline \multirow[t]{2}{*}{ Phenotype } & $\begin{array}{l}\text { blaZ } \\
\text { gene }\end{array}$ & $\begin{array}{c}\text { Nitrocefin } \\
\text { test }\end{array}$ & \multirow[t]{2}{*}{ B-lactamase level } \\
\hline & + & - & \\
\hline BIVRs $(n=18)$ & \multicolumn{2}{|c|}{$3(16.7 \%)$} & Undetectable \\
\hline Non-BIVRs $(\mathrm{n}=112)$ & \multicolumn{2}{|c|}{$22(19.6 \%)$} & Undetectable \\
\hline
\end{tabular}

These results clearly showed a tendency for blaZ gene positive BIVRs and few non-BIVRs to suppress the $B$ lactamase gene and not produce active $\beta$-lactamase. The mechanism of blaZ gene suppression was not investigated further.

These findings are in agreement with the results of Hirao et al., (2012) who found that, among 25 BIVRs, $23(92.0 \%)$ yielded negative results for the nitrocefin test and 21 of them $(84.0 \%)$ were blaZ-negative, and among 328 non-BIVRs, 200 isolates $(61.0 \%)$ yielded positive results for the nitrocefin test and the remaining $128(39.0 \%)$ gave negative results, $310(94.5 \%)$ were blaZ-positive, only $18(5.5 \%)$ were blaZ-negative (Fig. 3).

All the previous results clearly demonstrated a trend for BIVRs to lack the blaZ gene and don't secret active $\beta$-lactamase, whereas most non-BIVRs carried the $\beta$-lactamase gene and a major percent of them secreted active $B$ - lactamase. A good explanation of these results is that; the BIVRs, that produce undetectable level of B-lactamase, have cryptic mutations enabling them, in the presence of active $B$ lactam antibiotics, to up regulate the peptidoglycan metabolism and repair systems, so produce much peptidoglycan precursors with free D-Ala-D-Ala ends. The precursors bind with the free VA, decreasing the VA concentration in milieu below the VA MIC. The BIVRs begin to grow under such conditions, leading to VA resistance (Hirao et al., 2012).

On the other hand, the non-BIVRs, cannot up regulate the peptidoglycan metabolism in the 
absence or presence of the $\beta$-lactams, because they have the wild-type of peptidoglycan metabolism, so the VA concentration in milieu would remain above the MIC, and the organisms would be killed immediately by VA (Jacobs, 1997).

To find a good solution for treating of the BIVR infections, a phasing out (serial passage) of BIVRs in a medium not containing any antibiotic for 5 successive days, was done, and the response of the BIVRs was tested. The BIVR properties were phased out gradually to show the non-BIVR phenotype when tested by the BIVR screening test in the $5^{\text {th }}$ day. These findings are in agreement with the results of Hirao et al., (2012).

In conclusion, BIVRs gain vancomycin resistance only in presence of B-lactam antibiotics, so preserving B-lactams in milieu, by preventing $\beta$-lactamase production, either by lacking or suppressing the blaZ gene.

\section{Accordingly, we recommend that}

Avoid the concomitant use of B-lactam antibiotics and VA in treating VA sensitive MRSA that have tendency to become BIVR, and if there are Gram negative bacilli which are common co-pathogens treat them by other effective antibiotics. IF BIVRs isolated from a patient, B-lactams should be avoided for 5 successive days till the organisms become sensitive to VA, and during this period other effective antibiotics, other than the B-lactams, should be used.

\section{Abbreviations}

BIVR: $\quad$-lactam antibiotic-induced vancomycin-resistant MRSA; blaZ: Gene encoding ß-lactamase; CLSI: Clinical Laboratory Standard Institute; EB: Ethidium bromide; LZD: linezolide; MUHs: Mansoura
University Hospitals; MDICU: Medical diagnostics and infection control unit; MIC: Minimum inhibitory concentration; MRSA: Methicillin-resistant Staphylococcus aureus; MH: Mueller-Hinton; PBP: Penicillin binding protein; PCR: Polymerase chain reaction; VA: Vancomycin.

\section{Acknowledgement}

To all members in the 'Medical Microbiology and Immunology Department, Faculty of Medicine, Mansoura University, Egypt'.

\section{References}

Aushbel F, Brent R, Kingstone R, Moore D, Seidman J, Smith J, et al., (1990): Preparation of genomic DNA from bacteria. Cited by: Cuurent Protocols in Molecular Biology, Aushbel F, Brent R, Kingstone R, Moore D, Seidman J, Smith J and Struhl K. (eds.). P: 241. Green and Wiley, New York.

Bignardi GE, Woodford N, Chapman A, Johnson AP and Speller DC. (1996): Detection of the mecA gene and phenotypic detection of resistance in Staphylococcus aureus isolates with borderline or low-level methicillin resistance. J Antimicrob Chemother, 37: 53-63.

Boucher H, Miller LG and Razonable RR. (2010): Serious infection caused by methicillin-resistant Staphylococcus aureus. Clin Infect Dis, 51(Suppl 2): S183-S179.

Cheesbrough M. (2006): Microbiological tests. In Cheesbrough M. (Ed.), District Laboratory Practice in Tropical Countries (pp. 62-70). New York: Cambridge University Press.

Clinical and Laboratory Standards Institute; CLSI (2014): Performance Standards for Antimicrobial Susceptibility Testing; Twenty-Fourth Informational Supplement; CLSI document M100-S24. Wayne, PA. 
Cunha BA. (2008): Vancomycin revisisted: a reappraisal of clinical use. Crit Care Clin., 24: 393-420.

Davis LG, Dibner MD and Battey JF. (1986): Agarose gel electrophoresis. Cited by: Davis LG, Dibner MD and Battey JF. (eds.), Basic Methods in Molecular Biology, P: 58-61. Elsevier science publishing Co., New York.

Forbes BA, Sahm DF and Weissfeld AS. (2007): Staphylococcus, micrococcus and similar organisms. Baily and Scott's Diagnostic Microbiology (12th ed.): MOSBY Elsevier.

Hanaki H, Yamaguchi Y, Yanagisawa C, Uehara K, Matsui H, Yamaguchi Y, et al., (2005): Investigation of B-lactam antibiotic-induced vancomycin-resistant MRSA (BIVR). J Infect Chemother, 11: 104-106.

Hirao $Y$, Ikeda-Dantsuji1 $Y$, Matsuil $H$, Yoshida M, Hori S, Sunakawa K, et al., (2012): Low level ß-lactamase production in methicillin resistant staphylococcus aureus strains with B-lactam antibioticsinduced vancomycin resistance. BMC Microbiology, 12: 69.

Jacobs C. (1997): Life in the Balance: Cell walls and antibiotic resistance. Science, 278: 1731-1732.

Lowy F.D. (2003): Antimicrobial resistance: the example of Staphylococcus aureus. J. Clin. Invest., 111(9): 1265-1273.

Murray BE.(1998): Diversity among multidrugresistant Enterococci. Emerg. Inf. Dis., 4:37-47.

Perkins HR and Nieto M. (1974): The chemical basis for the action of the vancomycin group of antibiotics. Ann NY Acad Sci., $235 ; 348-363$.
Pinho MG, de Lencastre $\mathrm{H}$ and Tomasz A. (2001): An acquired and a native penicillin binding protein cooperate in building the cell wall of drug-resistant Staphylococci. Proc Nat Acad Sci., 98: 10886-10891.

Sakai F, Hanaki H, Barada K, Hirao Y, Inamatsu T, Nakae T, et al., (2010): A 25year trace of methicillin-resistant Staphylococcus aureus dissemination in a geriatric hospital in Japan. Internl J Gen Med., 3: 399-405.

Sarker SD, Nahar L and Kumarasamy Y. (2007): Microtitre plate based antibacterial assay incorporating resazurin as an indicator of cell growth, and its application in the in vitro antibacterial screening of phytochemicals. Methods, 42(4): 321-324.

Totsuka K, Shiseki M, Kikuchi K and Matsui Y. (1999): Combined effects of vancomycin and imipenem against methicillin-resistant Staphylococcus aureus (MRSA) in vitro and in vivo. $\mathrm{J}$ Antimicrob Chemother, 44: 455-460.

Yamaguchi Y, Hanaki H, Barada K, Inamoto T and Sunakawa K. (2003): Epidemiological investigation of MRSA with antagonistic effects of $\beta$-lactam antibiotic and vancomycin (in Japanese). Kansennshogaku Zasshi, 77: 661-6.

Yanagisawa C, Hanaki H, Matsui H, Ikeda S, Nakae T and Sunakawa K. (2009): Rapid depletion of free vancomycin in medium in the presence of B-lactam antibiotics and growth restoration in Staphylococcus aureus strain with B-lactam-induced vancomycin resistance. Antimicrob Agents Chemother, 53: 63-68.

\section{How to cite this article:}

Ahmed, E.S. Taha, Mohammad F. Badr, Fikry E.S. El-Morsy and Enas Hammad. 2017. Vancomycin-Resistant MRSA Induced by $\beta$-Lactam Antibiotics in Mansoura University Hospitals. Int.J.Curr.Microbiol.App.Sci. 6(12): 3606-3619. doi: https://doi.org/10.20546/ijcmas.2017.612.417 